Research Article

\title{
Failure Prediction of Two Types of Rocks Based on Acoustic Emission Characteristics
}

\author{
Bing Sun, ${ }^{1}$ Shanshan Hou, ${ }^{1}$ Jiehui Xie, ${ }^{2}$ and Sheng Zeng $\mathbb{D}^{3}$ \\ ${ }^{1}$ School of Civil Engineering, University of South China, Hengyang, Hunan 421001, China \\ ${ }^{2}$ School of Civil Engineering and Transportation, South China University of Technology, Guangzhou, Guangdong 430071, China \\ ${ }^{3}$ School of Resource and Environment and Safety Engineering, University of South China, Hengyang, Hunan 421001, China
}

Correspondence should be addressed to Sheng Zeng; usczengs@126.com

Received 12 April 2019; Accepted 9 June 2019; Published 23 June 2019

Academic Editor: Dong Zhao

Copyright (C) 2019 Bing Sun et al. This is an open access article distributed under the Creative Commons Attribution License, which permits unrestricted use, distribution, and reproduction in any medium, provided the original work is properly cited.

\begin{abstract}
The stability analysis of rock is an important basis to ensure the safe exploitation of underground resources and the reliable operation of space engineering. Uniaxial compression and acoustic emission (AE) tests were carried out on two common rock samples with strong rock burst tendency. The relationship between mechanical characteristics, AE characteristics, and rock burst tendency in the failure process of rock with different body types and the evolution of fractal characteristics of $\mathrm{AE}$ parameters were discussed. Based on the cusp mutation theory, the catastrophe model of AE characteristic parameters was established to quantify the instability mechanism of rock mass. The results show that the AE mutation rate (AEMR) of the cubic specimens increase from a low level to a high level gradually in the stable fracture stage, while that of the cylindrical specimens increase sharply to the maximum when the specimens are near failure. The AE cumulative energy curves of cubic specimens show a "step" rise, while that of cylindrical specimens show a "gradual" rise, and the rock burst process of cubic specimens is faster. The fractal dimension evolution mode of AE characteristic parameters of cubic specimens during uniaxial compression text is decline-rise-decline, while that of cylindrical specimen is decline-rise-decline-steeply rise. According to the periodic change of $\mathrm{AE}$ cumulative energy curve, combined with the rock failure cusp mutation model, the occurrence of rock burst can be well predicted, providing certain theoretical guidance for the stability analysis of underground engineering rock mass.
\end{abstract}

\section{Introduction}

The stability analysis of rock is of vital importance in underground construction, water conservancy, transportation, and other infrastructure projects, as well as open-pit mines, deep mines, and other resource mining projects. The practice shows that the failure of rock is directly related to the occurrence of engineering geological disasters such as surface subsidence and collapse, stope caving, and deep rock burst, which has posed great threat to the safety of construction personnel and equipment and seriously affected the progress of the project [1-3]. Therefore, the research on the deformation and failure of rock has been widely concerned.

From the perspective of the failure process, rock failure is the overall failure caused by microscopic defects dispersed in rock which continuously expand and penetrate to form macrocracks and converge to form large cracks along a certain direction under the action of external loads [4]. AE technology is an effective means to study the defect expansion of brittle materials such as rock. It can infer the change of rock internal behavior and invert the rock failure mechanism through the study of AE signals [5]. Domestic and foreign scholars have carried out a lot of researches on the rock failure by using $\mathrm{AE}$ technology. In terms of different AE signals, Kong et al. [6] selected the rock samples within original crack for uniaxial compression loading experiment and found that the value of $\mathrm{AE}$ counts and the trend of AE accumulated counts could qualitatively explain the damage evolution rule of the loaded rock samples. Zhang et al. [7] took AE energy, ringing count, rising time, and main frequency as 
characteristic parameters to perform clustering analysis on AE signals generated in the process of roadway rock burst and obtained three types of rock fracture corresponding to the AE signals. In order to study the changes of AE signals before rock failure, Yang et al. [8] conducted AE experiments on rock samples under different properties and stress conditions in the laboratory and believed that high intensity AE activity could be regarded as the precursor of brittle failure of rock, while relatively weak AE activity could be regarded as the precursor of brittle failure or semibrittle failure of rock. Wang et al. [3] studied the AE characteristics of the failure process of coal-rock samples under different loading rates and obtained three basic failure modes and rock burst proneness of coal-rock structure through uniaxial compression tests.

Since Xie and Pariseau [9] applied the damage mechanics and fractal geometry to the analysis of the rock fracture and established the fractal theory of rock, the failure process of rock based on the fractal characteristics has already been studied by many scholars. The results prove that both the time and space distributions of $\mathrm{AE}$ signals sequence have fractal characteristics [10, 11]. For example, Xie [12] et al. conducted uniaxial compression and AE experiments on layered rock salt samples, analyzed the relationship between the spatial distribution of fractal dimension of AE parameters and stress and energy release, and believed that the increase of fractal dimension corresponded to the decrease of stress and the increase of energy release. Gao et al. [13] calculated the correlation dimension $D$ of AE characteristic parameters of rock under different stress levels and concluded that the decrease of fractal dimension means the generation of main fracture or failure. Li et al. [14] carried out true triaxial multistage loading tests on coal samples, calculated the fractal dimension of AE counts of each loading step, and discussed the relationship between the fractal dimension change of AE parameters before rock failure and the "quiet period" of AE activity.

From the perspective of energy, rock failure is the mutation of energy dissipation in rock under certain conditions, and the elastic potential energy stored in rock is released with this sudden change [4]. Catastrophe theory is an effective tool to study the instability phenomenon of jumping [15], and it is widely used in the stability analysis of engineering rock mass such as open-pit slope [16, 17], surrounding rock of workshop and roadway $[18,19]$, roof of goaf [20], etc., prediction of dynamic disasters such as pressure bump [21], rock burst [22, 23], and water inrush [24] in deep engineering, and mechanism analysis of rock fracture failure $[25,26]$. The application of catastrophe theory can deepen the existing knowledge and deal with problems from a higher point of view.

To sum up, scholars have made a lot of meaningful achievements in the study of rock failure. In view of the common forms of underground supporting structures, uniaxial compression and $\mathrm{AE}$ tests were carried out on cubic and cylindrical granite and red sandstone with strong rock burst tendency. The fracture process of two types of rock and the evolution of fractal characteristics of $\mathrm{AE}$ parameters were analyzed, and the rock failure cusp mutation model was established based on cusp catastrophe theory. It is expected to enhance the monitoring capability of AE technology for rock mass stability and provide some guidance for the safe operation and maintenance of actual engineering.

\section{AE Tests}

2.1. Preparation of Specimens. The samples of granite and red sandstone are derived from a marble mine and a salt mine in Hunan Province, China. In order to study the difference between the fracture characteristics and $\mathrm{AE}$ parameters of two different types of rocks, $100 \times 100 \times 100 \mathrm{~mm}$ standard cubic specimens and $\varnothing 50 \times 100 \mathrm{~mm}$ standard cylindrical specimens were manufactured following the recommended standard of the International Society for Rock Mechanics (ISRM); the deviations between parallel top and bottom surfaces of any specimen were not allowed to exceed $2.5 \%$. The sample preparations are shown in Figure 1.

2.2. Specimen Devices and Method. The compression tests were carried out on the RMT150-B rock mechanical test system, developed by Wuhan Institute of Rock and Soil Mechanics, Chinese Academy of Sciences. The loading method utilized force control, and the loading rate was $0.005 \mathrm{MPa} / \mathrm{s}$. DS5-8B AE test apparatus was applied to collect the AE signals. In the experiment, two AE sensors were arranged on the specimen surface, of which the operating frequency is $60-400 \mathrm{kHz}$. Each sensor was equipped with a RS-35C type preamplifier. $30 \mathrm{~dB}$ threshold was selected for all sensors, and the preamplifier gain was $40 \mathrm{~dB}$. The equipment is shown in Figure 2. In order to reduce the friction effect and the noise of the end face, butter was applied on the upper and lower ends of the samples. Vaseline coupling agent was applied between the AE sensor and the sample and then fixed them with tape to ensure good contact and reduce the loss of AE signals. Before the test, the response of the sensor was measured to detect its response amplitude to the analog signal source, and the test can be started when it is normal. The stress-strain curves of different rocks under uniaxial compression are shown in Figure 3. The mechanical parameters of the rock material were obtained in the stress-strain curves of specimens, and the value of each rock burst tendency index $W_{C F}$ of each rock was calculated by using MATLAB. The results are shown in Table 1.

\subsection{Basic Mechanical Characteristics of Rock. According to} the stress-strain curves and mechanical characteristic parameters of cubic and cylindrical specimens, it can be seen that the strength of the cube specimens is larger than that of the cylindrical specimens due to its larger effective stiffness and the stronger resistance to deformation. At the same time, it can be seen that both the stress-strain curves of cubic and cylindrical specimens have initial compaction stage, linear elastic deformation, stable fracture stage, and failure and instability stage. The stress values of the two types of 


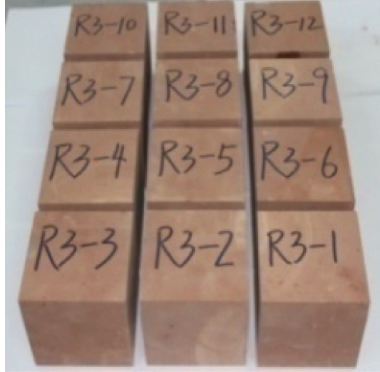

(a)

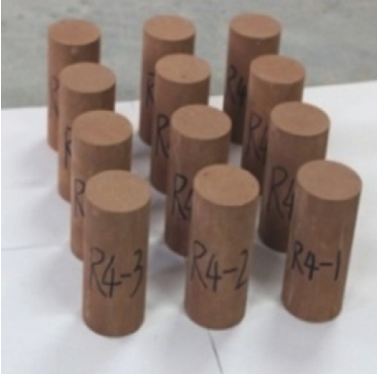

(b)

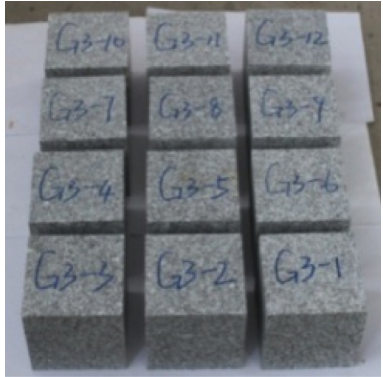

(c)

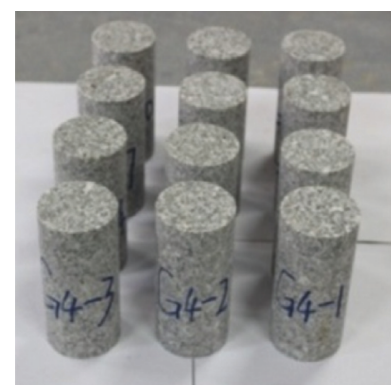

(d)

Figure 1: Test specimens. (a) Cubic red sandstone. (b) Cylindrical red sandstone. (c) Cubic granite. (d) Cylindrical granite.

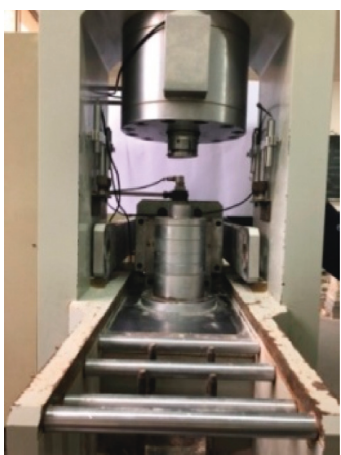

(a)

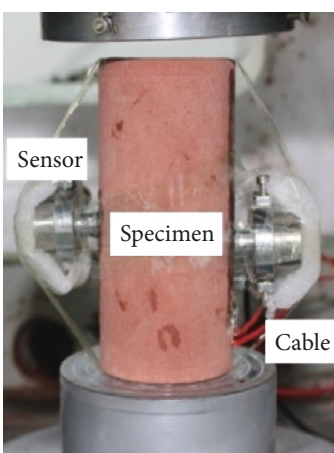

(b)

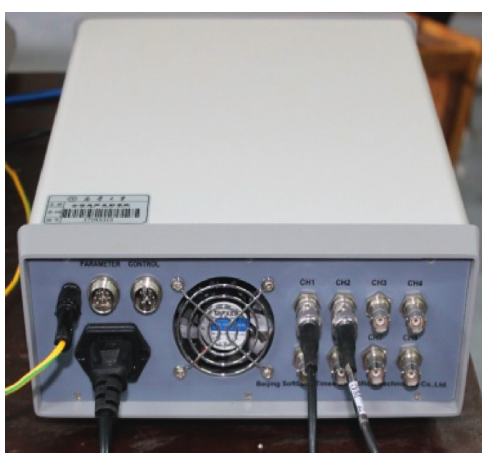

(c)

FIgURE 2: Experimental equipment. (a) Loading system. (b) Test sample. (c) AE test system.

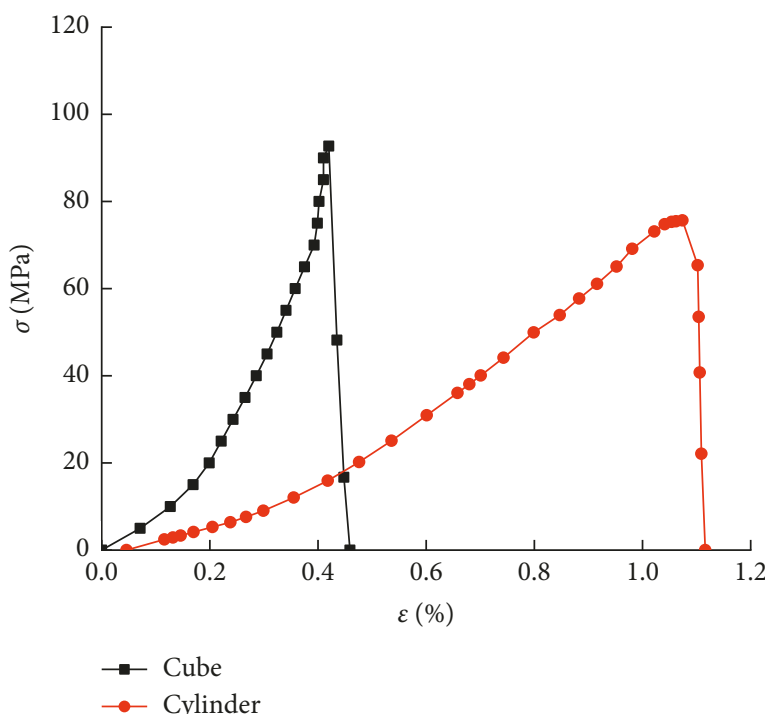

(a)

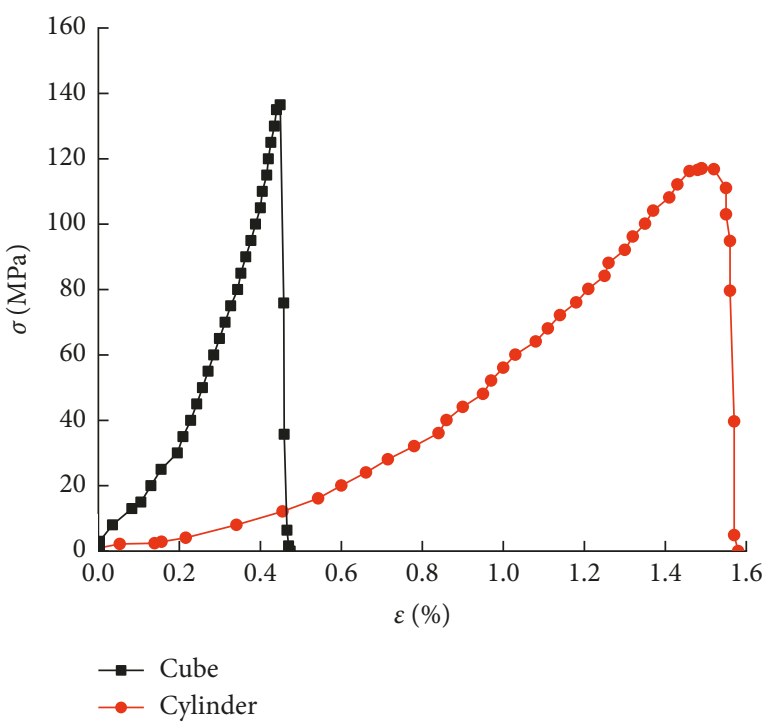

(b)

Figure 3: Stress-strain curves of different rock. (a) Red sandstone. (b) Granite.

TABLE 1: The mechanical parameters and rock burst tendency for different types of rocks.

\begin{tabular}{lcccc}
\hline Specimen type & Compressive strength $(\mathrm{MPa})$ & Elastic modulus $(\mathrm{GPa})$ & Poisson's ratio & Rock burst tendency $W_{C F}$ \\
\hline Cubic red sandstone & 82.50 & 37.94 & 0.18 & Strong $(21.35)$ \\
Cylindrical red sandstone & 64.67 & 37.90 & 0.18 & Strong (21.13) \\
Cubic granite & 136.50 & 47.95 & 0.20 & Strong (25.89) \\
Cylindrical granite & 120.24 & 47.90 & 0.20 & Strong (25.50) \\
\hline
\end{tabular}


rocks drop rapidly after the peak point, and the stress-strain curves of postpeak have only a very small section, which are typical brittle failure characteristic. Failure modes of different specimens under uniaxial compression are shown in Figure 4.

From the view of macroscopic failure, due to different aspect ratios, the fracture of cubic samples is the splitting failure almost parallel to the direction of axial loading and the crack propagation is complex, while the fracture of cylindrical samples is the shear failure which develops along the direction of about $45^{\circ}$, and the subcrack is less. In addition, the fracture surface area of red sandstone is large and the main crack is noncohesive due to the good internal homogeneity. However, the inhomogeneity of the internal microstructure in granite is relatively larger, and the ends are quickly compacted when the specimen is compressed, resulting in fracture and expansion failure. As the load continues to increase, a multifragmentation burst failure occurs eventually and the cracks are more dispersed, which is consistent with the result that granite has strong rock burst tendency [27].

\section{Analysis of AE Test Results}

3.1. Analysis of AE Characteristic Parameters in Fracture Process of Different Types of Rocks. The main sources of AE activity in rock include the development and expansion of fractures, the fracture of inclusions or cements, the relative dislocation of uneven mineral particles on the surface, and the formation of slip zones and the friction activities along the fracture surfaces. AE rate (AER) is one of the basic $\mathrm{AE}$ parameters to characterize the precursor of rock instability, which refers to the ringing count per unit time [28]. Assume that the sequence of AER obtained from experimental monitoring is as $\left\{\mathrm{AER}_{k}\right\}(k=1,2, \ldots, L)$. AEMR is the absolute value of the difference between the AER and the AER at the previous moment in the AER sequence $\left\{\mathrm{AER}_{k}\right\}$ $(k=1,2, \ldots, L)$. AEMR sequence $\left\{\operatorname{AEMR}_{k}\right\}(k=1,2, \ldots, L)$ can be obtained by differential and absolute value processing of AER sequence $\left\{\mathrm{AER}_{k}\right\}(k=1,2, \ldots, L)$. AEMR can inhibit the influence of friction on AE characteristics and highlight AE information caused by rock fracture development [29]. The AER time series has obvious stage characteristics, and combined with the trend of the AEMR curve, it can reflect the rock fracture development information more comprehensively and accurately. The AEMR and AER of different samples were statistically analyzed, and the results are shown in Figure 5.

According to the AEMR and AER curves in the process of rock failure, it can be seen that the AEMR curves are simpler and clearer, highlighting the $\mathrm{AE}$ information caused by rock fracture and development. Comparing the time sequence characteristics of AEMR of two rocks with different body types, it is found that the AEMR curves of the cube specimens present a periodic change from a low level to a high level in the stable fracture stage, and the AE events are more intensive, while the AEMR curves of the cylindrical specimens increase to the maximum abruptly when the specimens are close to failure, and the AE events are sparse. This is consistent with the fact that the crack propagation of cubic specimen is complex, while the subcracks of the cylindrical specimen are less.

3.2. Energy Evolution Analysis of Rock Burst Process with Different Body Types. Rock burst is the result of microcrack propagation and rapid release of elastic strain energy in rock under certain stress conditions, and the sudden release of energy is the essential cause of rock burst disaster $[30,31]$.The uniaxial compression test of rock can be regarded as the rock burst activity under special stress conditions [32]. In order to analyze the energy evolution characteristics of rocks with different body types in the process of rock burst, the AE energy rate and AE cumulative energy were statistically analyzed, and the results are shown in Figure 6.

According to the characteristics of AE energy rate and AE cumulative energy curves of different specimens, the rock burst process of the specimens can be divided into four stages: quiet period, particle ejection, severe side ejection with particle, and burst instability. Through comparing the characteristics of $\mathrm{AE}$ energy rate and $\mathrm{AE}$ cumulative energy time series in the process of rock failure with different types, it is found that the AE cumulative energy curves of cubic specimens show a "step" increase, that is, there is a temporary period of energy release in the process of rock failure with cubic specimens, and every time the AE cumulative energy curve appears a platform, it indicates that the rock is accumulating energy for the reprojection of the flanks and particles. However, the $\mathrm{AE}$ cumulative energy curves of the cylindrical specimens are smooth and rise gradually, indicating that the energy release is continuous during the failure process. This is in line with the fact that the crack develops rapidly during the failure of the cylindrical specimens, while the crack develops relatively slowly in cubic specimens after flange and particle ejection.

The energy in rock burst process not only shows the nonuniform accumulation in space but also the nonstable transformation in time [33]. The duration of each stage of rock instability process was statistically analyzed, and the results are shown in Table 2.

From the comparison of the time proportion of each stage in the process of rock burst of rock with different body types, it can be seen that the calm period of cube specimen is longer while the duration of rock burst is shorter, which shows that the rock burst of cubic specimen occurs faster, and the development process from particle ejection to violent ejection is more rapid. Once the phenomenon of particle ejection occurs, rock burst will occur in a relatively short time.

\section{Fractal Analysis of AE Parameters of Rocks with Different Types}

The failure process of rock instability can be regarded as the internal disorder, microdamage, and microdamage 


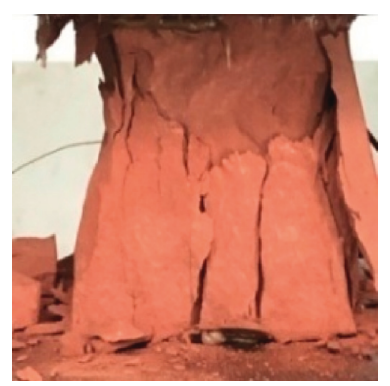

(a)

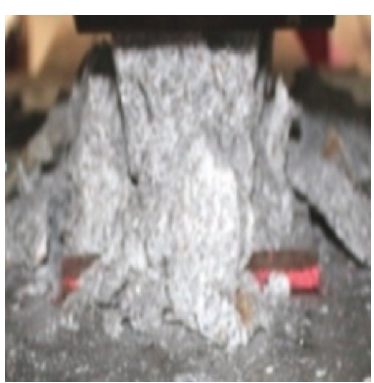

(b)

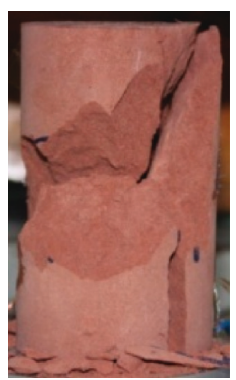

(c)

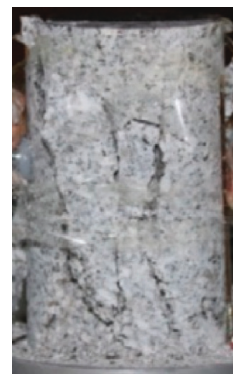

(d)

FIGURe 4: Failure patterns of different specimens. (a) Cubic red sandstone. (b) Cubic granite. (c) Cylindrical red sandstone. (d) Cylindrical granite.
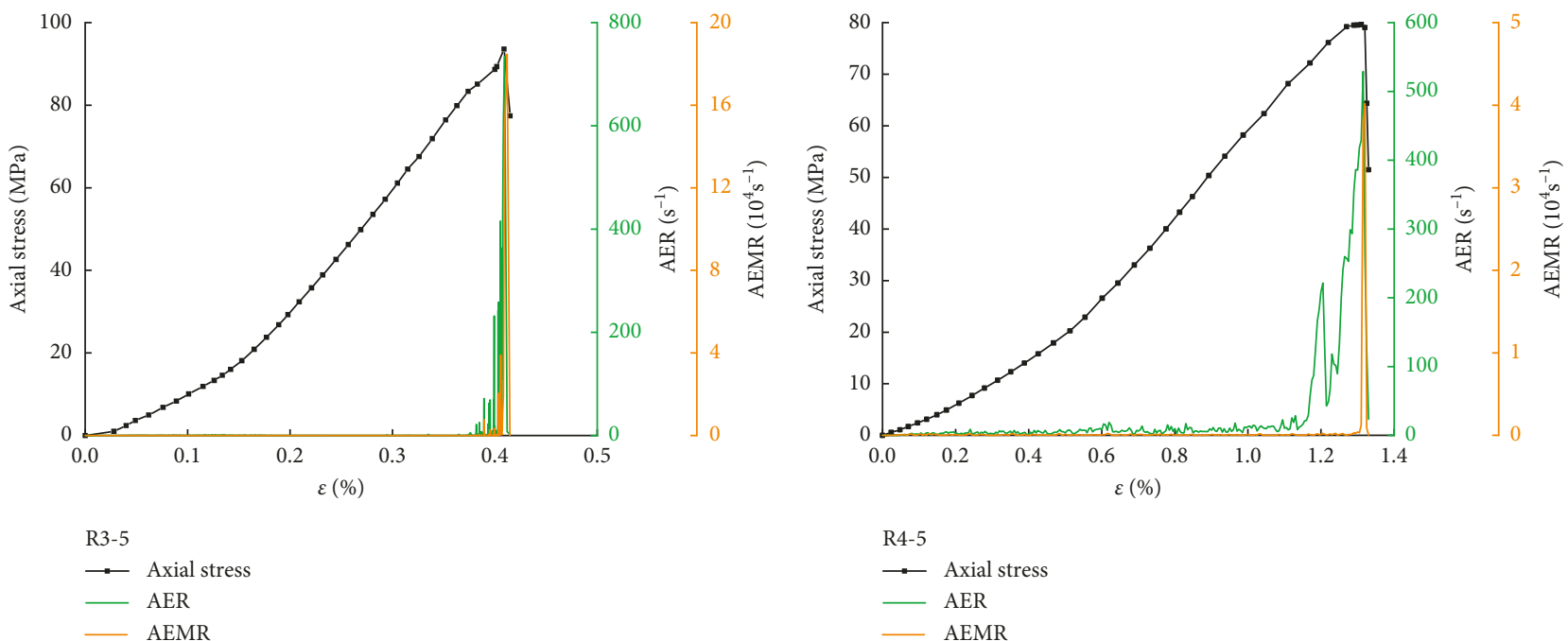

R4-5

$\rightarrow$ Axial stress

— AER

AEMR

(a)

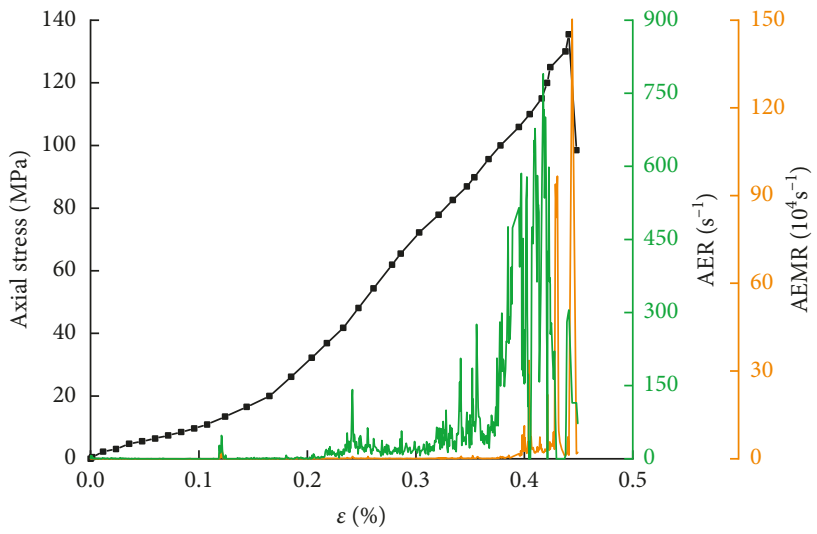

G3-1

$\rightarrow$ Axial stress

— AER

_ AEMR

(d)

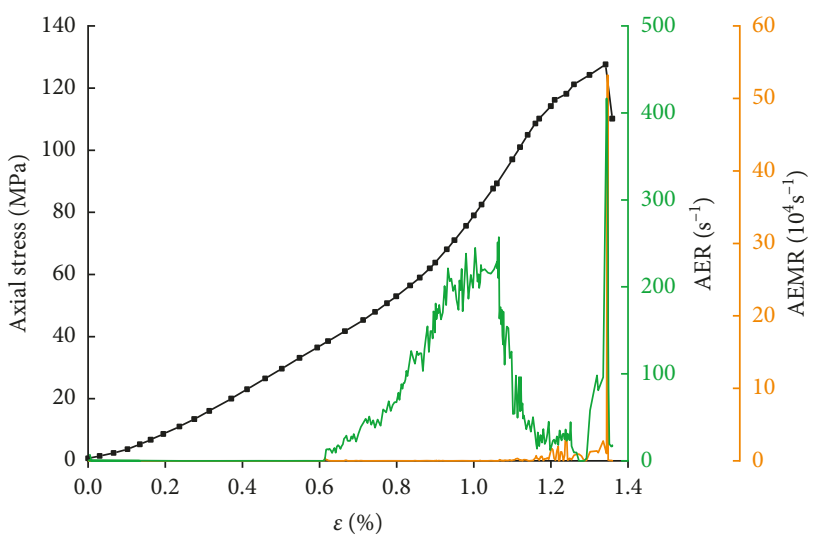

G4-9

$\rightarrow$ Axial stress

— AER

(c)

FIgURE 5: Time series characteristics of AEMR and AER for different samples. (a) Cubic red sandstone. (b) Cylindrical red sandstone. (c) Cubic granite. (d) Cylindrical granite.

which scattered throughout the rock from disorder to order and formed the main fracture evolution process under the action of external force. As a measure of disorder, fractal dimension can well reflect the statistical evolution law of these microdamages. The correlation dimension $D$ of AE parameters is a new indicator which 

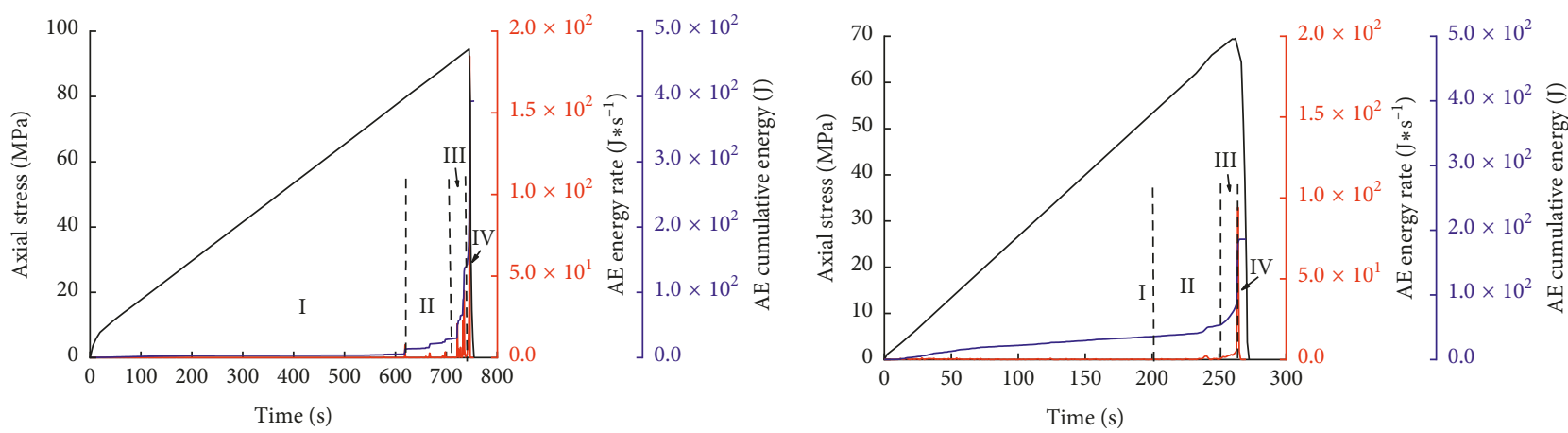

R3-5

- Axial stress

_ AE energy rate

_ AE cumulative energy

R4-5

- Axial stress

AE energy rate

_ AE cumulative energy

(a)

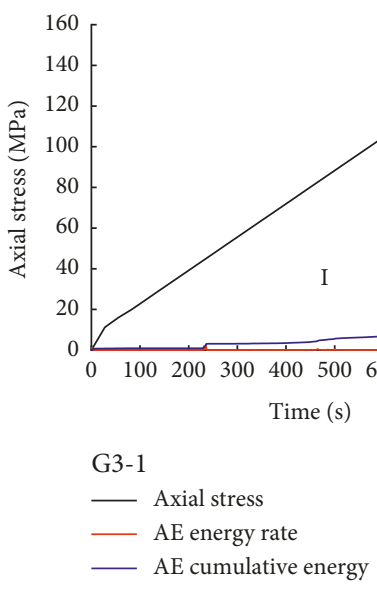

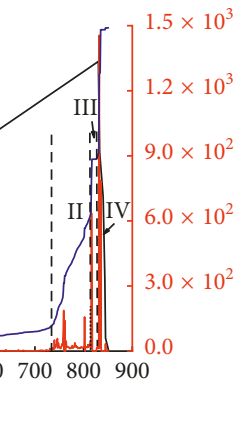

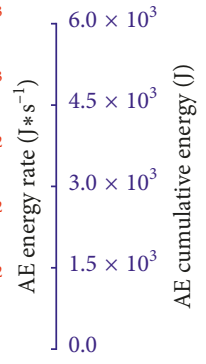

(b)

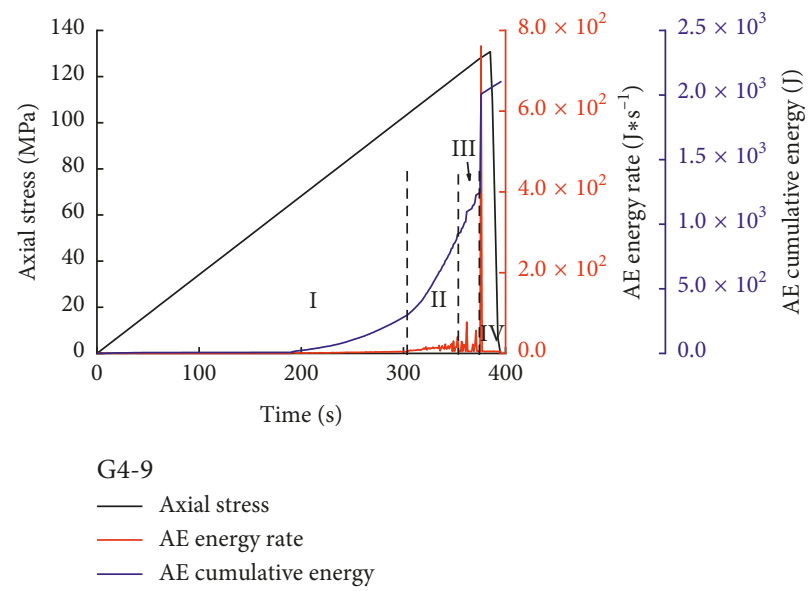

(d)

FIgURE 6: Time series characteristics of AE energy rate and AE cumulative energy of different specimens. (a) Cubic red sandstone. (b) Cylindrical red sandstone. (c) Cubic granite. (d) Cylindrical granite.

TABle 2: Time ratios of each stage in the rock burst process of different specimens.

\begin{tabular}{lcccc}
\hline $\begin{array}{l}\text { Specimen } \\
\text { type }\end{array}$ & $\begin{array}{c}\text { The quiet period } \\
\text { duration (s) }\end{array}$ & $\begin{array}{c}\text { Percentage of the quiet } \\
\text { period duration (\%) }\end{array}$ & $\begin{array}{c}\text { Duration from violent band stage to } \\
\text { burst instability stage (s) }\end{array}$ & $\begin{array}{c}\text { Percentage of duration from violent band } \\
\text { stage to burst instability stage (\%) }\end{array}$ \\
\hline R3-5 & $0 \sim 621$ & 82.25 & $721 \sim 746$ & 3.18 \\
R4-5 & $0 \sim 201$ & 74.44 & $252 \sim 265$ & 4.81 \\
G3-1 & $0 \sim 734$ & 85.68 & $815 \sim 835$ & 2.35 \\
G4-9 & $0 \sim 304$ & 76.77 & $354 \sim 376$ & 3.03 \\
\hline
\end{tabular}

can describe the mechanical behavior of rock and its structural damage changes well, and the evolution process of crack generation and propagation in rock can be further revealed by analyzing the change of correlation dimension $D[34]$.

4.1. Calculation Model of Correlation Fractal Dimension D. The improved G-P algorithm is used to calculate the correlation dimension. The calculation steps are as follows.

Any sequence of AE parameters can be regarded as a sequence set with a capacity of $n$ :

$$
X=\left\{x_{1}, x_{2}, \ldots, x_{n}\right\} .
$$

Take the number of the first $m$ as a vector of $m$-dimensional space $(m<n)$ :

$$
X_{1}=\left\{x_{1}, x_{2}, \ldots, x_{m}\right\}
$$

Move back one number and then take $m$ number to form the second vector:

$$
X_{2}=\left\{x_{2}, x_{3}, \ldots, x_{m+1}\right\} .
$$

By analogy, $n=n-m+1$ vector, as follows: 


$$
X_{m}=\left\{x_{n-m+1}, x_{n-m}, \ldots, x_{n}\right\} .
$$

Their correlation function is $w$, as follows:

$$
W(r)=\frac{1}{N^{2}} \sum_{i=1}^{N} \sum_{i=1}^{N} H\left[r(k)-\left|X_{i}-X_{j}\right|\right]
$$

where $H$ is Heaviside function and $H(u)=\left\{\begin{array}{ll}0, & u<0, \\ 1, & u \geq 0,\end{array} r(k)\right.$ is a given scale function. In order to avoid the dispersion of data, take the scale $r=k r_{0}$, where $k$ is a proportional coefficient. For each given scale $r(k)$, it corresponds to $W(r(k))$. For the given $g$ scales, $g$ cross-point $(\ln W(r(k))$, ln $r(k)$ ) can be obtained in the double logarithmic coordinate system, where $k=1,2, \ldots, g$. Then, carry out unitary linear regression for the $g$ coordinate points, and the slope of the regression line is the related fractal dimension value $D$, i.e.,

$$
D=\frac{\ln C(k)}{\ln k}
$$

The phase space dimension $m$ has a great influence on the correlation dimension $D$; the same phase space dimension $m$ should be determined when calculating the correlation dimension $D$ of different AE sequences [35]. Taking G3-1 as an example, the relationship between phase space dimension $m$ and correlation dimension $D$ was calculated by MATLAB, as shown in Figure 7. The correlation dimension $D$ tends to be stable when $m>6$, so $m$ is taken as 4 .

4.2. Fractal Characteristics of AE Parameters of Rocks with Different Body Types. Using the calculation program of correlation dimension $D$ in MATLAB, the AE energy rate, AER, and AEMR of each rock were processed by unary linear regression, and the correlation coefficients were more than 0.9 , suggesting that the AE parameter series had fractal characteristics and self-similarity in the time domain. The distribution curves of correlation dimension $D$ of the $\mathrm{AE}$ energy rate, AER, and AEMR with each loading stress for different specimens were obtained, as shown in Figure 8.

According to the variation process of fractal dimension of the AE parameters above, the failure process of rock can be divided into microfracture compaction stage, new fracture generation stage, and microfracture convergence to main fracture stage. At the initial stage of loading, the primary microcracks within the specimen gradually closed under the action of load, so the correlation dimension $D$ presents a downward trend in a small range. With the continuous increase of external load, the rock sample starts to enter the elastic stage, the original cracks in rock sample have basically been completely closed, and new cracks gradually appeared and some minor damages occurred. Therefore, the correlation dimension $D$ changes repeatedly in this stage, but the overall trend is upward. When the load stress ratio increases to about 0.6 , the sample begins to enter the yield stage, a large number of new cracks spread within the specimen, and the correlation dimension $D$ has reached the maximum value at this time; Thereafter, the overall

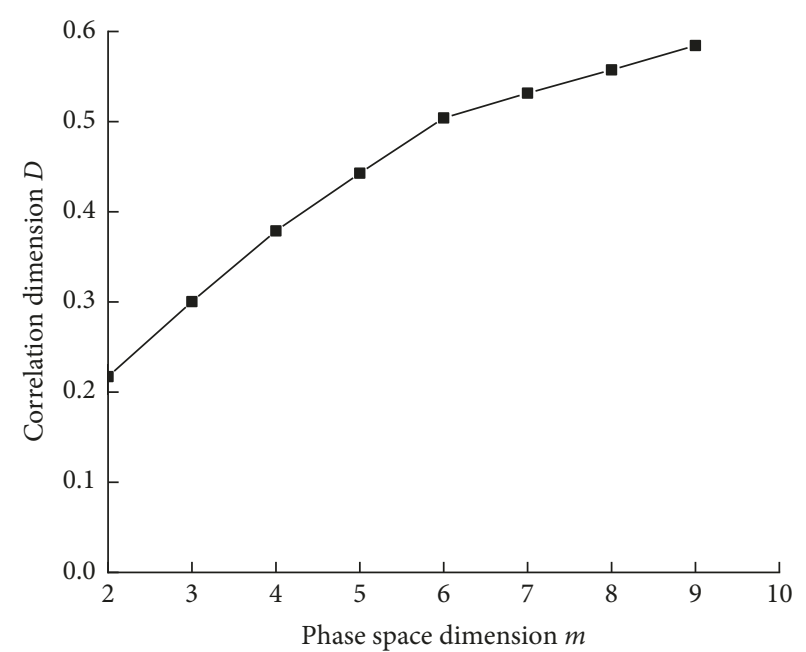

Figure 7: Relationship curve between phase space dimension $m$ and correlation dimension $D$.

correlation dimension $D$ shows a downward trend, which means that the microfracture of larger scale failure in the specimen increases and gradually approaches the main fracture surface in an orderly manner, and the specimen is about to lose stability.

The AEMR can filter out well the AE activity generated by the friction of the mineral structure inside the granite specimen. Comparing the correlation dimension $D$ of AEMR of specimens with different body types, it is found that the correlation dimension $D$ of AEMR of cylindrical specimens increases sharply when the loading stress ratio is about 0.9 , while that of cube specimens decreases gradually to a lower level after reaching the maximum, and no such phenomenon occurs. Analyzing the reasons, it is believed that the larger aspect ratio makes the local characteristics of yield weakening of cylindrical specimens more obvious, and slip friction occurs when microcracks connect and penetrate into each other to form macrofracture surface and has obvious directionality, resulting in the shear failure of rock samples. Therefore, the correlation dimension $D$ presents a phenomenon of steep increase in the stage of failure and instability [36]. The cubic specimen tends to be in a threedimensional stress state under compression, and the friction between machine head and end of sample is isotropic. There are more materials reaching yield to weaken after the main fracture of the specimen is formed; the rock samples after failure are easy to be peeled off layer by layer. Therefore, the correlation dimension $D$ of the AEMR of the specimen gradually decreases to a lower level after reaching the maximum, without any steep increase.

\section{Catastrophe Model for Predicting Instability of Rock}

5.1. Cusp Catastrophe Theory. The potential function of cusp catastrophe can generally be described as

$$
v(x)=x^{4}+p x^{2}+q x,
$$




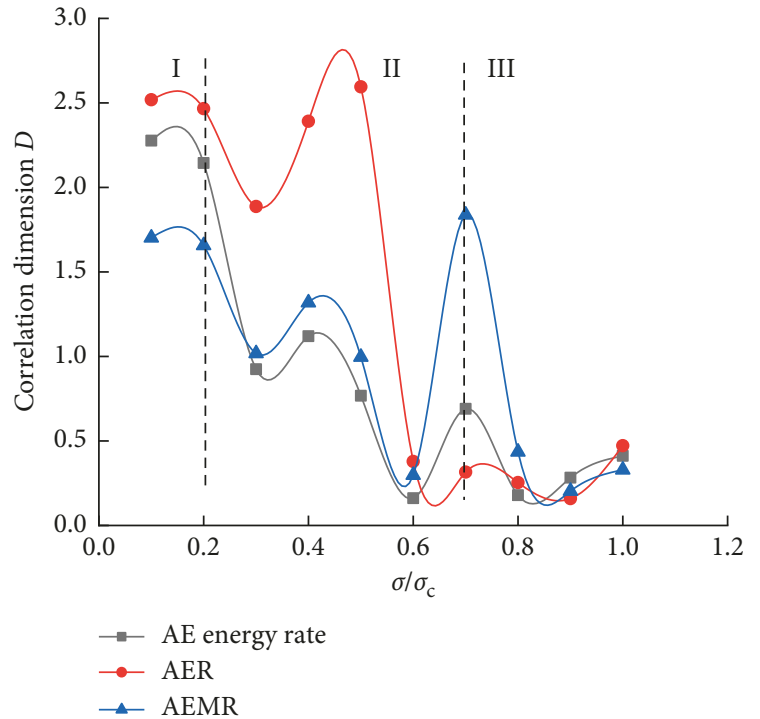

(a)

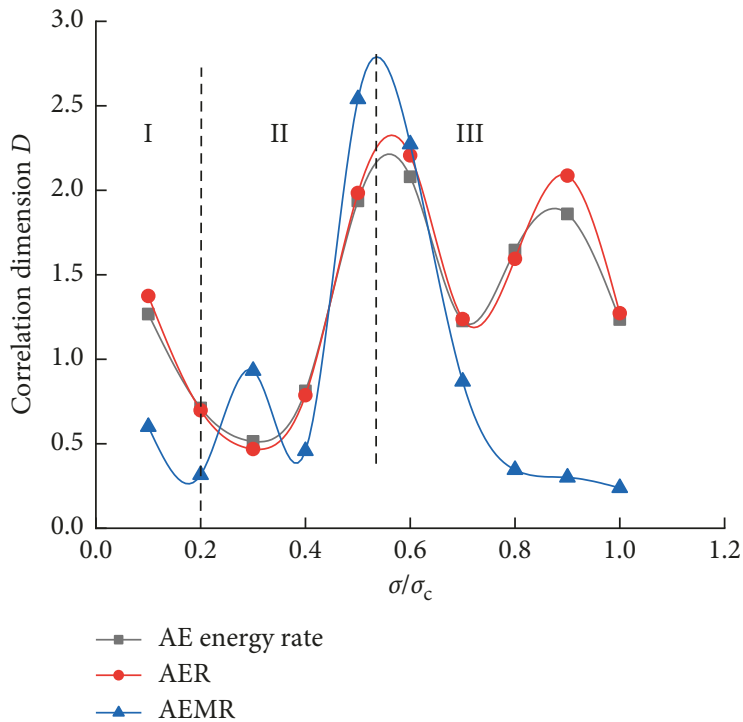

(c)

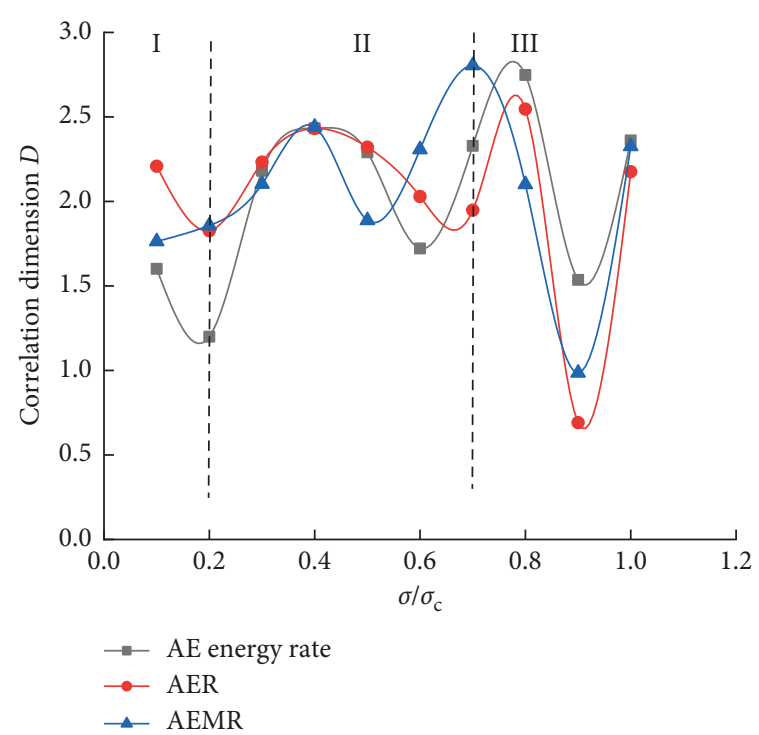

(b)

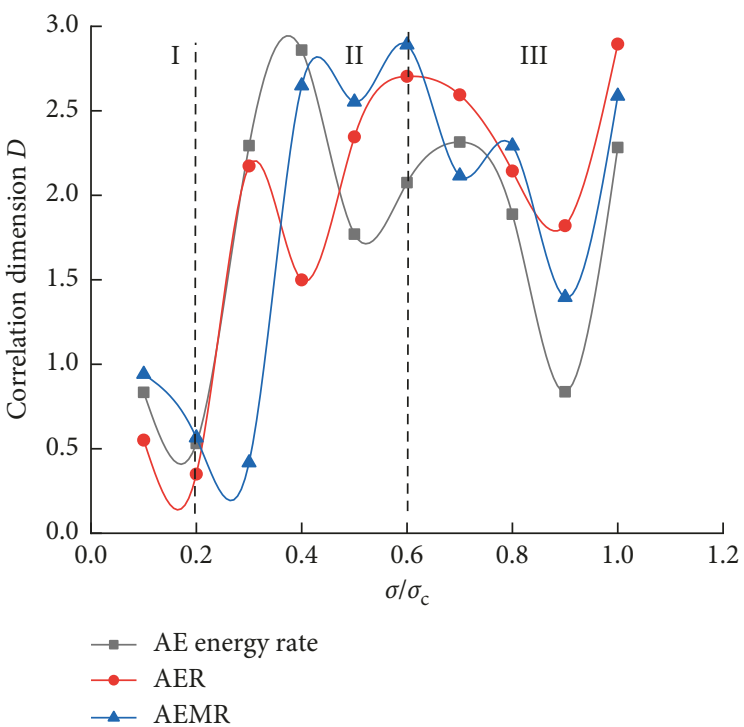

(d)

Figure 8: Changes of fractal dimension of specimens with different body types. (a) Cubic red sandstone. (b) Cylindrical red sandstone. (c) Cubic granite. (d) Cylindrical granite.

where $x$ is the state variable and $p$ and $q$ are the control variables; the potential energy function of the equilibrium surface equation is

$$
v(x)^{\prime}=4 x^{3}+2 p x+q=0 .
$$

As the control variables $p$ and $q$ change, the corresponding points move on the equilibrium surface. The middle lobe of the equilibrium surface corresponds to the unstable state of the system.

The bifurcation equation of the potential function is

$$
F=8 p^{3}+27 q^{2}=0 .
$$

When the control variables $p$ and $q$ satisfy the bifurcation equation, the system can transfer from one equilibrium state to another. According to the catastrophe rule: when $F>0$, the system state is stable; when $F=0$, the system is in critical stable state; and when $F<0$, the system will break and enter the unstable state. Formula (9) can be used to predict the failure of rock.

\subsection{Prediction Model of Rock Burst Based on AE Parameters.} The key problem of rock burst prediction based on $\mathrm{AE}$ characteristic parameters and mutation theory is how to use the AE monitoring data in the cusp mutation model to judge whether rock burst occurs or not. Among them, the AER can be regarded as the continuous variable function $x(t)$ of time variable $t$. By Taylor expansion, the first four terms can be intercepted to meet the accuracy requirements, as follows: 


$$
y=x(t)=a_{0}+a_{1} t+a_{2} t_{2}+a_{3} t^{3}+a_{4} t^{4} .
$$

Let $x=t-n$, and transform equation (4) to the standard form of cusp mutation:

$$
V(x)=x^{4}+p x^{2}+q x .
$$

In the expression, the expression for $n, p$, and $q$ is

$$
\left\{\begin{array}{l}
n=\frac{a_{3}}{4 a_{4}} \\
p=-6 n^{2}+\frac{a_{2}}{4 a_{4}} \\
q=8 n^{2}-\frac{2 n a_{2}}{a_{4}}+\frac{a_{1}}{a_{4}} .
\end{array}\right.
$$

AER substitution formula (4) is used to obtain $a_{i}$ by least square method, and then substitution formula (6) is used to calculate $p$ and $q$ values. According to $F$ value, rock burst can be judged.

The least square method is used to obtain $a_{i}$ by substituting the AER into equation (10), and then $p, q$ and $F$ can be obtained. The rock burst can be determined according to $F$ value. When $F>0$, the rock mass near the measuring point is in stable state; when $F=0$, the rock mass near the measuring point is in critical state; and when $F<0$, rock burst occurs near the observation point. In order to predict the possibility of rock burst more accurately, the process of rock burst was divided into different time periods according to the change of AE accumulated energy curves, and the AER in each stage was brought into the prediction model. The prediction results are shown in Tables 3-6.

According to the prediction results, it can be seen that the rock burst occurs when the specimens of cubic red sandstone, cubic granite, and cylindrical granite enter the stage of flake grain ejection after the quiet period, and that of cylindrical red sandstone only occurs in the stage of specimen bursting and instability. Combined with the change of AE cumulative energy curves, it can be seen that the slope of the AE cumulative energy curves of cubic red sandstone, cubic granite, and cylindrical granite specimens rises abruptly after the quiescence stage, releasing a large amount of energy, so rock burst is prone to occur. This is consistent with the greater rock burst tendency index $W_{C F}$ of cubic red sandstone, cubic granite, and cylindrical granite. Therefore, the mutation model can be used to judge whether rock burst occurs in rocks with strong rock burst tendency when the cumulative energy of the specimen increases suddenly in practical engineering and to prevent and control the occurrence of rock burst.

\section{Conclusions}

Aiming at the stability problem of rock with strong rock burst tendency in underground engineering, uniaxial compression and $\mathrm{AE}$ tests were carried out on cubic and cylindrical red sandstone and granite. Based on AE characteristics and catastrophe theory, the failure characteristics
TABLE 3: Rock burst prediction of cubic red sandstone.

\begin{tabular}{|c|c|c|c|c|}
\hline \multirow{2}{*}{$\begin{array}{l}\text { Forecast } \\
\text { periods }\end{array}$} & \multicolumn{3}{|c|}{ AER } & \multirow{2}{*}{$\begin{array}{c}\text { Prediction } \\
\text { results }\end{array}$} \\
\hline & $p$ & $q$ & $F$ & \\
\hline $180-201$ & $-4.059 e+01$ & $1.903 e+02$ & $4.428 e+05$ & $\begin{array}{c}\text { Rock burst } \\
\text { does not } \\
\text { occur }\end{array}$ \\
\hline $201-251$ & $1.357 e+02$ & $1.395 e+02$ & $1.948 e+07$ & $\begin{array}{c}\text { Rock burst } \\
\text { does not } \\
\text { occur }\end{array}$ \\
\hline $251-265$ & $3.831 e+01$ & $1.394 e+02$ & $-7.465 e+04$ & $\begin{array}{c}\text { Rock burst } \\
\text { occurred }\end{array}$ \\
\hline
\end{tabular}

\begin{tabular}{lcccc}
\hline $\begin{array}{l}\text { Forecast } \\
\text { periods }\end{array}$ & $p$ & AER & $F$ & $\begin{array}{c}\text { Prediction } \\
\text { results }\end{array}$ \\
\hline $601-621$ & $-4.808 e+01$ & $1.198 e+03$ & $3.786 e+07$ & $\begin{array}{c}\text { Rock burst } \\
\text { does not } \\
\text { occur } \\
\text { Rock burst } \\
\text { occurred } \\
721-721\end{array}$ \\
$721-746$ & $-1.037 e+02$ & $8.357 e+01$ & $-8.721 e+06$ & $\begin{array}{c}\text { Rock burst } \\
\text { occurred }\end{array}$ \\
\hline
\end{tabular}

TABLE 4: Rock burst prediction of cylindrical red sandstone.

TABLE 5: Rock burst prediction of cubic granite.

\begin{tabular}{|c|c|c|c|c|}
\hline \multirow{2}{*}{$\begin{array}{l}\text { Forecast } \\
\text { periods }\end{array}$} & \multicolumn{3}{|c|}{ AER } & \multirow{2}{*}{$\begin{array}{c}\text { Prediction } \\
\text { results }\end{array}$} \\
\hline & $p$ & $q$ & $F$ & \\
\hline $264-304$ & $5.340 e+01$ & $7.762 e+02$ & $1.749 e+07$ & $\begin{array}{c}\text { Rock burst } \\
\text { does not } \\
\text { occur }\end{array}$ \\
\hline $304-354$ & $1.662 e+03$ & $3.050 e+04$ & $-1.573 e+10$ & $\begin{array}{c}\text { Rock burst } \\
\text { occurred }\end{array}$ \\
\hline $354-376$ & $-4.810 e+02$ & $4.147 e+03$ & $-4.260 e+08$ & $\begin{array}{c}\text { Rock burst } \\
\text { occurred }\end{array}$ \\
\hline
\end{tabular}

\begin{tabular}{lcccc}
\hline $\begin{array}{l}\text { Forecast } \\
\text { periods }\end{array}$ & $p$ & $\begin{array}{c}\text { AER } \\
q\end{array}$ & $F$ & $\begin{array}{c}\text { Prediction } \\
\text { results }\end{array}$ \\
\hline $700-734$ & $-9.290 e+02$ & $1.589 e+04$ & $4.005 e+08$ & $\begin{array}{c}\text { Rock burst } \\
\text { does not } \\
\text { occur } \\
\text { Rock burst } \\
\text { occurred } \\
\text { Rock burst } \\
\text { occurred }\end{array}$ \\
\hline $814-835$ & $-1.649 e+02$ & $-6.218 e+01$ & $-3.577 e+07$ & $-2.080 e+05$ \\
\hline
\end{tabular}

TABLE 6: Rock burst prediction of cylindrical granite.

of rocks with different body types were discussed. The main conclusions are as follows:

(1) AEMR can better identify the AE information caused by rock fracture development, and the combination with AER can reflect the information of rock fracture development more comprehensively. The AEMR of the cubic specimens increases from a low level to a high level gradually in the stable fracture stage, and the $\mathrm{AE}$ events are more intensive. However, the 
AEMR of the cylindrical specimens increases to the maximum sharply when the specimen is close to failure, and the $\mathrm{AE}$ events are sparse, which is consistent with the macroscopic fracture phenomenon of the specimens.

(2) According to the law of energy accumulation and release in each stage of the rock burst process and the time effect of energy, the AE cumulative energy curves of cubic red sandstone and granite specimens show a "step" rise, while those of cylindrical red sandstone and granite specimens show a "gradual" rise. The process of rock burst in cubic specimens occurs faster, and the development process from particle ejection to severe ejection is more rapid.

(3) The correlation dimension $D$ can characterize well the development process of damage and failure in rock. The evolution mode of fractal dimension of cubic specimens during uniaxial compression texts is decline-rise-decline, while that of cylindrical specimens is decline-rise-decline-steeply rise. When the correlation dimension $D$ decreases considerably, it means that the main fracture has been formed, which can be the characteristic information of rock mass instability to a certain extent.

(4) Combining with the periodic change of cumulative energy curve, the cusp mutation model established based on AER can be used to better predict whether rock burst occurs or not. It is a comprehensive method for rock burst prediction, which improves the accuracy of rock burst prediction and provides a more reliable guarantee for engineering prediction of rock burst.

\section{Data Availability}

The data used to support the findings of this study are available from the corresponding author upon request.

\section{Conflicts of Interest}

The authors declare that there are no conflicts of interest regarding the publication of this paper.

\section{Acknowledgments}

This work was supported by the National Natural Science Foundation for Young Scientists of China (grant no. 51204098), the Natural Science Foundation of Hunan Province (grant nos. 2018JJ2331 and 2017JJ3274), and the Postgraduate Science Funds of the University of South China (2018KYY121).

\section{References}

[1] J.-p. Liu, S.-d. Xu, Y.-h. Li, and G. Lei, "Analysis of rock mass stability based on mining-induced seismicity: a case study at the Hongtoushan copper mine in China," Rock Mechanics and Rock Engineering, vol. 52, no. 1, pp. 265-276, 2019.
[2] G. Wang, S. Gong, L. Dou, W. Cai, X. Yuan, and C. Fan, "Rockburst mechanism and control in coal seam with both syncline and hard strata," Safety Science, vol. 115, no. 6, pp. 320-328, 2019.

[3] S. Wang, H. Li, W. Wang, D. Li, and W. Yang, "Experimental study on strength, acoustic emission, and energy dissipation of coal under naturally and forcedly saturated conditions," Advances in Civil Engineering, vol. 2018, no. 1, pp. 1-12, 2018.

[4] H. P. Xie, R. D. Peng, Y. Ju et al., "On energy analysis of rock failure," Chinese Journal of Rock Mechanics and Engineering, vol. 24, no. 15, pp. 2603-2608, 2005.

[5] M. C. He, J. L. Miao, and J. L. Feng, "Rock burst process of limestone and its acoustic emission characteristics under truetriaxial unloading conditions," International Journal of Rock Mechanics and Mining Sciences, vol. 47, no. 2, pp. 286-298, 2010.

[6] X. G. Kong, E. Y. Wang, X. Q. He et al., "Mechanical characteristics and dynamic damage evolution mechanism of coal samples in compressive loading experiments," Engineering Fracture Mechanics, vol. 4, no. 5, pp. 1-10, 2018.

[7] Y. B. Zhang, Z. Yang, X. L. Yao et al., "Experimental study on acoustic emission signal and fracture characteristics of rock burst in granite roadway," Journal of China Coal Society, vol. 43, no. 1, pp. 95-104, 2018.

[8] H. Yang, G. Wen, Q. Hu, Y. Li, and L. Dai, "Experimental investigation on influence factors of acoustic emission activity in coal failure process," Energies, vol. 11, no. 6, pp. 1414-1430, 2018.

[9] H. P. Xie and W. G. Pariseau, "Fractal character and mechanism of rockbursts," Chinese Journal of Rock Mechanics and Engineering, vol. 12, no. 1, pp. 28-37, 1992.

[10] M. X. Li, Y. H. Song, and G. Zhang, "Study on the fractal characteristics of rock in the prediction of rockburst," RSC Advances, vol. 7, no. 68, pp. 43073-43082, 2017.

[11] X. Z. Wu, X. X. Liu, Z. Z. Liang et al., "Experimental study of fractal dimension of $\mathrm{AE}$ serials of different rocks under uniaxial compression," Rock and Soil Mechanics, vol. 33, no. 12, pp. 3561-3569, 2012.

[12] H. P. Xie, J. F. Liu, Y. Ju, J. Li, and L. Z. Xie, "Fractal property of spatial distribution of acoustic emissions during the failure process of bedded rock salt," International Journal of Rock Mechanics and Mining Sciences, vol. 48, no. 8, pp. 1344-1351, 2011.

[13] F. Gao, J. J. Li, and X. Y. Li, "Fractal analysis of the characteristics of acoustic emission of rock," Journal of Wuhan University of Technology, vol. 27, no. 7, pp. 67-69, 2005.

[14] D. X. Li, E. Y. Wang, K. X. Guo et al., "Fractal characteristics of acoustic emissions from coal under multi-stage true-triaxial compression," Journal of Geophysics and Engineering, vol. 15, no. 5, pp. 2021-2032, 2018.

[15] J. Liu, J. Bao, Y. Yin, and S. Yang, "Applications of catastrophe theory in engineering: a review," Journal of Computational and Theoretical Nanoscience, vol. 12, no. 12, pp. 5739-5744, 2015.

[16] X. X. Chen, Z. Qin, H. L. Fu et al., "Analysis on stability of water-saturation slopes based on cusp catastrophic model," Geology and Exploration, vol. 54, no. 2, pp. 0376-0380, 2018.

[17] K. Yang, T. Wang, and Z. Ma, "Application of cusp catastrophe theory to reliability analysis of slopes in open-pit mines," Mining Science and Technology, vol. 20, no. 1, pp. 71-75, 2010.

[18] Y. Zhao, J. W. Zhang, and S. F. Yuan, "Safety evaluation for stability of underground powerhouse surrounding rock based on catastrophe theory," Chinese Journal of Rock Mechanics and Engineering, vol. 33, no. S2, pp. 3973-3978, 2014.

[19] C.-p. Zhang, K.-h. Han, Q. Fang, and D.-1. Zhang, "Functional catastrophe analysis of collapse mechanisms for deep tunnels 
based on the Hoek-Brown failure criterion," Journal of Zhejiang University Science A, vol. 15, no. 9, pp. 723-731, 2014.

[20] W. Fu, D. Song, and Y. Y. Tan, "Study of stability and evolution indexes of gobs under unloading effect in the deep mines," Geomechanics and Engineering, vol. 14, no. 5, pp. 439-451, 2018.

[21] Y. H. Guo and Q. Chen, "Prediction of rock burst risk based on mutation theory," Journal of China Coal Society, vol. 49, no. 10, pp. 115-118, 2017.

[22] H. Zhou, S. C. Hu, J. J. Lu et al., "Rock burst liability analysis under slab-fractured body combination," Chinese Journal of Rock and Soil Mechanics, vol. 35, no. S2, pp. 1-7, 2014.

[23] T. Li, C. Ma, M. Zhu, L. Meng, and G. Chen, "Geomechanical types and mechanical analyses of rockbursts," Engineering Geology, vol. 222, no. 5, pp. 72-83, 2017.

[24] D. B. Xu, S. Y. Cao, Y. X. Xu et al., "Evaluation of water inrush risk from coal floor based on catastrophe theory," Coal Mine Safety, vol. 45, no. 12, pp. 197-200, 2014.

[25] Y. Zhao, Q. Peng, W. Wan, W. Wang, and B. Chen, "Fluidsolid coupling analysis of rock pillar stability for concealed karst cave ahead of a roadway based on catastrophic theory," International Journal of Mining Science and Technology, vol. 24, no. 6, pp. 737-745, 2014.

[26] Z.-x. Liu, M. Lan, S.-y. Xiao, and H.-q. Guo, "Damage failure of cemented backfill and its reasonable match with rock mass," Transactions of Nonferrous Metals Society of China, vol. 25, no. 3, pp. 954-959, 2015.

[27] G. Li and C.-A. Tang, "A statistical meso-damage mechanical method for modeling trans-scale progressive failure process of rock," International Journal of Rock Mechanics and Mining Sciences, vol. 74, no. 1, pp. 133-150, 2015.

[28] J. W. Fan and L. Z. Tang, "Application of acoustic emission rate and energy rate in rock failure," Metal Mine, vol. 409, no. 7, pp. 140-142, 2010.

[29] X. Gao, S. J. Liu, J. W. Huang et al., "The influence of strain rate on $\mathrm{AE}$ characteristics during rock deformation," Chinese Journal of Rock Mechanics and Engineering, vol. 37, no. 4, pp. 887-897, 2018.

[30] F. Wang and R. Kaunda, "Assessment of rockburst hazard by quantifying the consequence with plastic strain work and released energy in numerical models," International Journal of Mining Science and Technology, vol. 29, no. 1, pp. 93-97, 2019.

[31] J. Xu, J. Jiang, N. Xu, Q. Liu, and Y. Gao, “A new energy index for evaluating the tendency of rockburst and its engineering application," Engineering Geology, vol. 230, no. 9, pp. 46-54, 2017.

[32] B. F. Li, "Study on burst tendency differentiation index of 2\# coal seam in Qianqiu coal mine," Journal of Safety Science and Technology, vol. 10, no. 5, pp. 62-67, 2014.

[33] M. He, W. Nie, L. Han, and L. Ling, "Microcrack analysis of Sanya grantite fragments from rockburst tests," Mining Science and Technology, vol. 20, no. 2, pp. 238-243, 2010.

[34] X. Kong, E. Wang, S. Hu, R. Shen, X. Li, and T. Zhan, "Fractal characteristics and acoustic emission of coal containing methane in triaxial compression failure," Journal of Applied Geophysics, vol. 124, no. 1, pp. 139-147, 2016.

[35] W. D. Liu, X. Zhu, Q. Xu et al., "Acoustic emission of rock and its fractal feature under uniaxial compression," Water Resources and Hydropower Engineering, vol. 48, no. 9, pp. 181185, 2017.

[36] Q. B. Meng, L. J. Han, H. Pu et al., "Effect of the size and strain rate on the mechanical behavior of rock specimens," Journal of China University of Mining \& Technology, vol. 45, no. 2, pp. 233-243, 2016. 


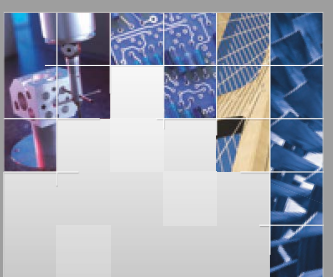

\section{Enfincering}
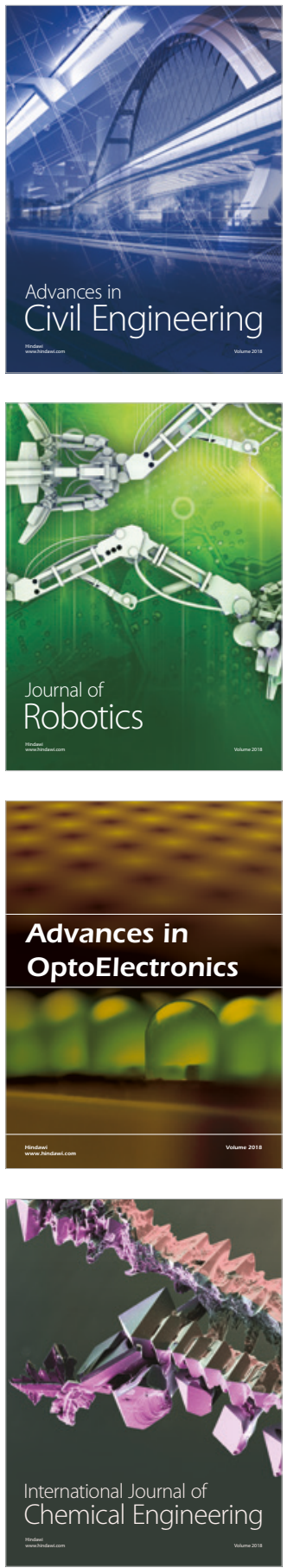

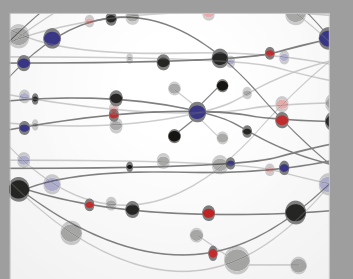

\section{Rotating \\ Machinery}

The Scientific World Journal

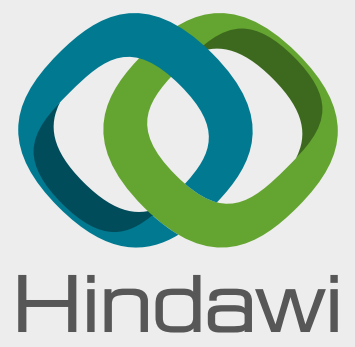

Submit your manuscripts at

www.hindawi.com
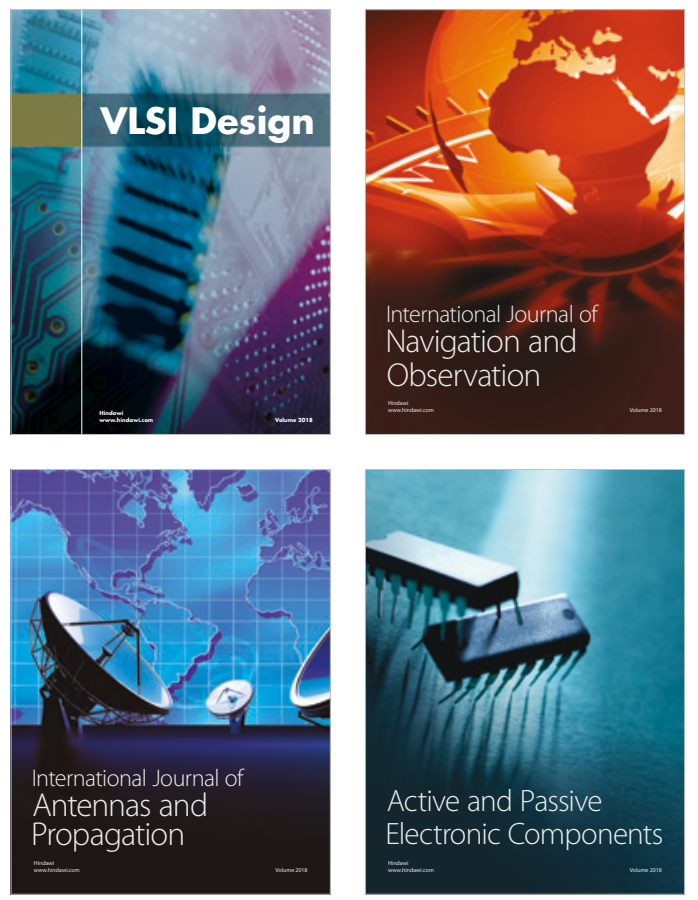
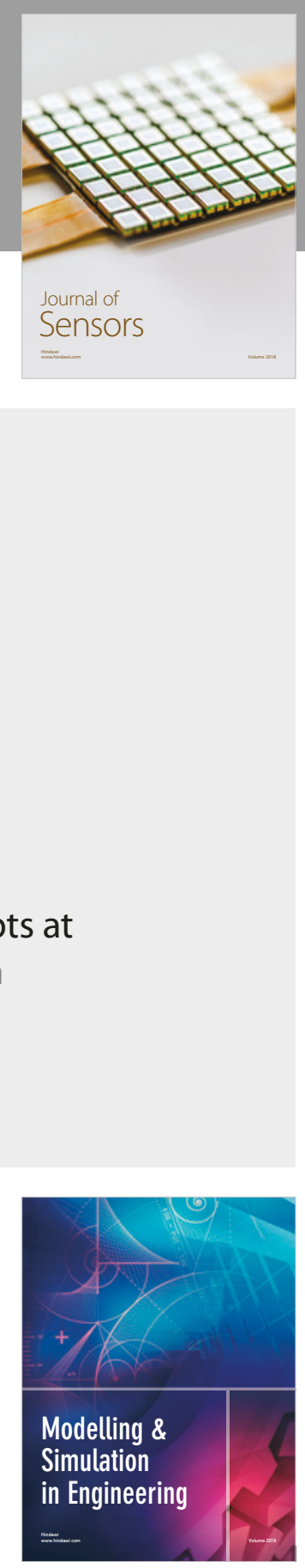

\section{Advances \\ Multimedia}
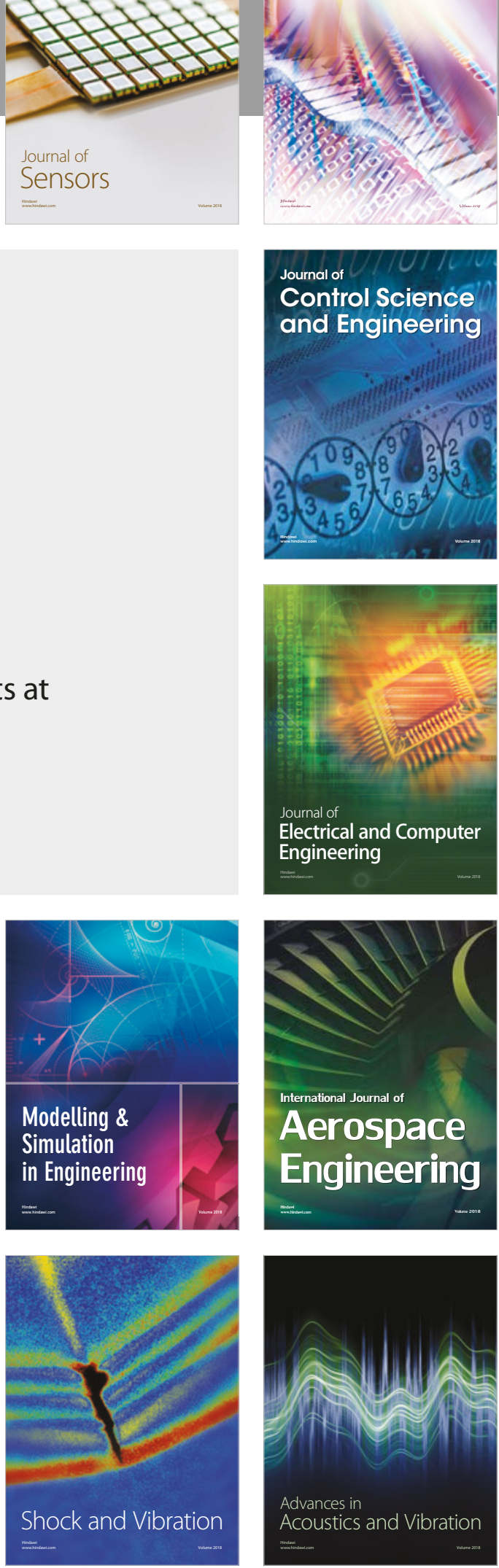